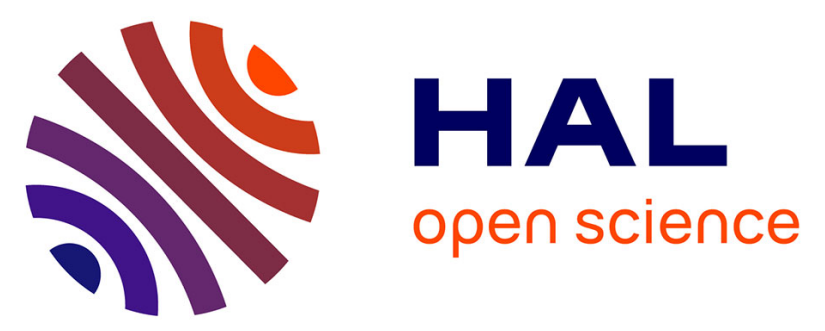

\title{
Biliary cirrhosis and sepsis are two risk factors of failure after surgical repair of major bile duct injury post-laparoscopic cholecystectomy.
}

Laurent Sulpice, S. Garnier, M. Rayar, B. Meunier, Karim Boudjema

\section{- To cite this version:}

Laurent Sulpice, S. Garnier, M. Rayar, B. Meunier, Karim Boudjema. Biliary cirrhosis and sepsis are two risk factors of failure after surgical repair of major bile duct injury post-laparoscopic cholecystectomy.. Langenbeck's Archives of Surgery, 2014, 399 (5), pp.601-8. 10.1007/s00423-014-1205-7 . hal-01067815

\section{HAL Id: hal-01067815 \\ https://hal.science/hal-01067815}

Submitted on 24 Sep 2014

HAL is a multi-disciplinary open access archive for the deposit and dissemination of scientific research documents, whether they are published or not. The documents may come from teaching and research institutions in France or abroad, or from public or private research centers.
L'archive ouverte pluridisciplinaire HAL, est destinée au dépôt et à la diffusion de documents scientifiques de niveau recherche, publiés ou non, émanant des établissements d'enseignement et de recherche français ou étrangers, des laboratoires publics ou privés. 


\section{Clean Version of revised manuscript}

Biliary cirrhosis and sepsis are two risk factors of failure after surgical repair of major bile duct injury post laparoscopic cholecystectomy

L.Sulpice ${ }^{1,2 \dagger}$, MD.PhD, S.Garnier ${ }^{1 \dagger}$, MD, M.Rayar ${ }^{1}, M D$, B.Meunier ${ }^{1}$, MD, K.Boudjema ${ }^{1,2}$ MD.PhD

1 Service de chirurgie hépatobiliaire et digestive, Hôpital Pontchaillou Université de Rennes 1 , Rennes, France

2 INSERM, UMR 991, Foie, métabolisme et cancer, Université de Rennes 1, Rennes, France

$\uparrow$ The two first authors have equally participated to this article.

This work was presented as an oral communication to the 115 congress of French Association of Surgery, Paris, September 2013

Running title: The results of major bile duct injury repair

\section{Correspondence:}

Pr Karim Boudjema and Doctor Laurent Sulpice

Service de Chirurgie Hépatobiliaire et Digestive, Hôpital Pontchaillou, Centre Hospitalier Universitaire, Université de Rennes 1, Rennes, France

Email: karim.boudjema@chu-rennes.fr

Doctor Laurent Sulpice

Service de Chirurgie Hépatobiliaire et Digestive, Hôpital Pontchaillou, Centre Hospitalier Universitaire, Université de Rennes 1, Rennes, France

Telephone: + 33299284265 Fax: + 33299284129 Email: laurent.sulpice@chu-rennes.fr

Keywords: Laparoscopic cholecystectomy; Bile duct injury; Repair; Long-term results 
Conflicts of interest: The authors have no conflicts of interest to declare Funding: The study received no external support

Category of submission: Original article

Authors' contributions: LS conceived and designed the study, undertook the analysis and interpretation of data, and wrote and finalized the manuscript. SG collected data, undertook the analysis and wrote the manuscript with LS. MR provided the statistical analysis. BM revised the manuscript. KB revised the manuscript and gave the final approval for publication. 


\section{ABSTRACT \\ Background}

Major bile duct injury (MBDI) remains frequent after laparoscopic cholecystectomy (LC) reaching to 0.3 to $0.6 \%$ and is associated with a significant mortality rate. The aim of this study was to retrospectively analyze the factors likely to influence the long-term results of surgical repair for MBDI occurring after LC.

\section{Methods}

Medical records of patients referred to our referral center from January 1992 to January 2010 for management of bile duct injury following LC were retrospectively analyzed, and patients with MBDI were identified. Clinicopathological factors likely to influence long-term results after surgical repair were assessed by univariate and multivariable analysis.

\section{Results}

During the study period, 38 patients were treated for MBDI. These 38 patients underwent Roux-en-Y hepaticojejunostomy (HJ) or HJ revision in $25(66 \%)$ and $13(34 \%)$ cases, respectively. The median follow-up period was 93 (26-204) months. A Clavien-Dindo postoperative morbidity class >3 occurred in 10 (26\%) cases and was independently associated with a surgical repair performed during a sepsis period $(\mathrm{OR}=102.5$ IC 95\% [7.12; 11352], p <0.007). Long-term results showed that biliary strictures occurred in 5 (13\%) cases and were associated with sepsis $(\mathrm{p}<0.006)$, liver cirrhosis $(\mathrm{p}<0.002)$ and postoperative complications $(\mathrm{p}<0.012)$. Multivariate analysis revealed that only liver cirrhosis remained predictive of stricture $(\mathrm{OR}=26.4$, IC95\% [2; 1018], $\mathrm{p}<0,026)$

\section{Conclusion}

When MBDI occurs following LC, HJ seems to be the optimal treatment but should not be performed during a sepsis period. Long-term results are significantly altered by the presence of a biliary cirrhosis at time of repair. 


\section{INTRODUCTION}

Cholecystectomy is one of the most frequently performed surgeries, with approximately 50,000 and 750,000 procedures performed annually in France and the United States, respectively [1]. The advent of laparoscopy has led to a significant increase in bile duct injury (BDI) rates, now reaching 0.3 to $0.6 \%[2,3]$ and mainly occurring during the learning curve [4]. In spite of Strasberg's "critical view of safety", new studies and new recommendations about the management of biliary disease have not yet significantly reduced the rate of BDI [57]. Recently, Fullum et al reported the results of a Nationwide survey of cholecystectomies and showed that the only risk factors of BDI were : i)male gender; ii) age>60 years and iii) academic hospital status. In this series, laparoscopic cholecystectomy was not associated with an increased risk of BDI [8]. The most important factor mainly correlated for improving the outcomes of cholecystectomies, remains the expertise of the surgeon [9,10]. MBDIs correspond to type E of Strasberg's classification and includes all types of sections of the common bile duct or its primary radicles [2,6]. Moreover, major BDIs are frequently associated with arterial injuries, i.e., a section of the right branch or the main trunk of the hepatic artery [11]. When MBDI occurs, mortality rates can reach $9 \%$ versus $0.45 \%$ when absent [12].

Whereas minor BDIs (i.e., leakage from the cystic duct or lateral injury of the common bile duct) can be easily treated endoscopically, MBDIs primarily require surgical repair. The goldstandard surgery is Roux-en-Y hepaticojejunostomy (HJ) as described by Couinaud, combined or not combined with liver resection [13-15]. However, the optimal care of major BDIs, including the timing of repair, the type of surgery and the factors effecting worse outcomes, remain widely debated. Moreover, an accurate assessment of the repair results requires a long follow-up because some complications such as anastomotic stricture or secondary biliary cirrhosis may occur several years after surgical repair.

Although numerous studies have reported the incidence and results of major BDIs [16-21], very few have focused on very long-term outcomes. The aim of the present study was to analyze the factors likely to influence very long-term results after primary or secondary surgical repair of post LC MBDI in a tertiary referral center. 


\section{METHODS}

\section{Patients}

The study population included all patients with BDI who were transferred to our institution between January 1992 and January 2010. Only patients with major BDI were analyzed. MBDI corresponds to type E of Strasberg's classification.

The clinical data were retrospectively collected and analyzed after Institutional Review board approval was obtained.

The collected data included age, sex, ASA Score, local sepsis, cholestasis (GGT serum over twice normal rate), presence or lack of jaundice and presence or lack of liver cirrhosis due to biliary obstruction at the time of repair in referral center and vascular injuries associated with BDI. Accordingly, CT scan was performed for each patient in order to search vascular injury before surgery in our center. Delay between the onset of MBDI diagnosis and time of transfer at our referral center was also assessed.

Ongoing sepsis was assessed in the presence of at least one of the following features, independently of previous surgery: leukocytosis $>15000 / \mathrm{mL}$, fever $>38.5^{\circ} \mathrm{C}$, angiocholitis episodes, peritonitis or intra-abdominal abscess [12]. The delay between the onset of MBDI diagnosis and surgical management was defined as follows: immediate (perioperative or under $72 \mathrm{~h}$ ), intermediate (between $72 \mathrm{~h}$ to 6 weeks) or late (over 6 weeks) [22].

The number of biliary anastomoses performed at time of repair was sorted into two groups: 1 and more than 1. The level of the anastomoses (on the common bile duct, on the confluence or on the hepatic duct), the use of biliary stenting and the necessity of liver resection were also collected for analysis.

Postoperative morbidity was classified according to the Clavien-Dindo Score (CDS) during the initial hospital stay or within 30 days after surgery if the patient was discharged [23]. Major postoperative complications were defined by a CDS of 3 or over. Moreover, patient death during the initial hospital stay or within 30 days after surgery if the patient was discharged defined postoperative mortality.

\section{Surgical repair}

All patients referred to our center for MBDI repair underwent first $\mathrm{HJ}$ or redo $\mathrm{HJ}$ with or without associated liver resection. All of the procedures were performed by a senior hepatic surgeon. The enteric loop length was $80 \mathrm{~cm}$, as measured with a ruler. All anastomoses were 
stented via transjejunal drain using the Völker technique. When liver resection was necessary, it consisted either in segment $4 \mathrm{a}$ and partially 5 resection to expose the biliary confluence from the top or a right hepatectomy when BDI had led to right liver atrophy. Systematically, a wedge biopsy of the liver was carried out to evaluate the impact of biliary obstruction.

\section{Long-term follow-up}

An update of the clinical, biological and ultrasonography outcome of all patients was performed between December 2011 and March 2012.

Good long-term results were defined by the absence of clinical symptoms, normality of hepatic laboratory tests and absence of dilatation of intrahepatic bile duct on ultrasonography performed at least one time per years after repair.

\section{Statistical analysis}

Quantitative variables were expressed as the mean \pm standard deviation (SD) or the median value with the $25^{\text {th }}$ and $75^{\text {th }}$ percentile and compared using Student's t-test or Wilcoxon test, as appropriate. The qualitative variables were expressed as numbers and percentages and compared with the results of Chi-squared or Fisher's exact tests, as appropriate. All variables with $\mathrm{p}<0.15$ in univariate analysis, as well as variables supposed to have a clinical influence on the complications rate as well as stenosis, were entered into a multiple logistic regression model. A variable selection procedure was performed using the stepwise procedure (backward method) based on minimalizing the AIC (Akaïke Information Criterion).

A p value of $<0.05$ was considered to be statistically significant. All statistical analysis were performed using R statistical software, version 2.15.1 (http://www.r-project.org/). 


\section{RESULTS}

\section{Demographic data and injury characteristics}

During the study period, 60 patients were referred to our center for BDI. Among them, 38 patients (15 men, 23 women, median age 61 (range: 33 to 88)) had MBDI. Ten (26.3\%) of the 38 had associated right hepatic artery interruption. No patient presented cirrhosis at the time of LC.

\section{Surgical management prior referral (Fig. 1)}

Twelve patients $(32 \%)$ were immediately referred without any attempt to repair. A previous surgical attempt to repair was performed in 26 cases $(68 \%)$, including primary repair over a TTube, bilio-biliary anastomosis and HJ in 17 (45\%), 1 (3\%) and 8 (21\%) cases, respectively. A second surgical attempt to repair prior to referral was performed in $6(23 \%)$, i.e., HJ in 5 $(13 \%)$ cases and repair over a T-Tube in $1(3 \%)$ case. The time elapsed between the onset of MBDI and repair before referral was immediate in 15 (39\%), intermediate in 7 (18\%) cases and late in $4(11 \%)$ patients.

\section{Surgical management and postoperative outcomes after repair in our center}

Twenty-five (66\%) patients underwent primary Roux-en-Y HJ, and 13 (34\%) patients underwent reconstruction of a previous HJ. Median length of hospital stay was 11 [5-55] days. In 9 cases (23.7\%), liver resection was associated with HJ. Among the 38 cases of the series, $15(39 \%)$ had sepsis, as defined previously, at the time of surgery and 35 (92\%) patients had cholestatis. Jaundice was present in $16(42 \%)$ cases. Secondary biliary cirrhosis due to obstruction was found in 7 (18\%) cases upon histological examination of the liver specimen. There was no cirrhosis due to other reason.

Table 2 reports the outcome of the 38 patients after surgical repair in our center. Postoperative biliary leakage occurred in 10 cases (26\%). Biliary leakage required redo surgery in $4(10 \%)$ cases and percutaneous drainage in $6(16 \%)$ cases. There was no postoperative mortality.

\section{Risk factors for perioperative major morbidity after repair (Table 2)}

Among the 17 variables assessed by univariate analysis, repair performed during a sepsis phase $(\mathrm{p}<0.001)$ and the presence of a cirrhotic liver $(\mathrm{p}<0.06)$ were related to major morbidity after repair. Multivariable analysis revealed that only the repairs performed during a sepsis 
period (OR 102.5 IC 95\% [7.1; 11352.3], p<0.007) remained a significant independent risk factor for major morbidity.

\section{Long-term results of biliary repair and risk factors for biliary stricture (Table 3)}

The median follow-up was 93 months (range: 26 to 204).

During follow-up, the overall mortality was $13 \%$ (5 cases). The cause of death was cardiovascular disease in 2 cases at months 60 and 142, respectively. Colon and breast cancer were responsible for death in two cases at 173 and 70 months, respectively. One (3\%) patient died due to biliary sepsis on postoperative month 39 after major BDI repair.

Post-repair biliary stricture occurred in $5(13 \%)$ cases (Table 3). The median delay between repair and the onset of stricture was 60 months (range: 9 to 158). These 5 patients were operated during a sepsis period. All 5 patients with stricture required a redo surgery by reconstruction of HJ. Redo surgery was successful in 2 (5\%) cases; 1 patient died due to sepsis, and $2(5 \%)$ patients eventually required a liver transplantation for secondary biliary cirrhosis.

At the end of the follow-up, a good result (i.e., laboratory tests within the normal range and absence of dilatation of intrahepatic bile duct) was obtained in 30 (79\%) cases. Three patients (8\%) still described angiocholitis episodes without visible biliary stricture and were successfully treated with prolonged treatment with quinolones.

Among the 18 factors assessed by univariate analysis, repair performed during a sepsis period $(\mathrm{p}<0.006)$, the presence of a cirrhotic liver $(\mathrm{p}<0.002)$ and the occurrence of major postoperative complication $(\mathrm{p}<0.012)$ were significantly related to biliary stricture. Multivariable analysis revealed that only cirrhosis (OR 26.4, IC95\% [2;1018.14], p<0.026) remained a significant independent risk factor for biliary stricture. 


\section{DISCUSSION}

To date, MBDIs remain frequent, plateauing at $0.3-0.6 \%$ of all cases of $\operatorname{LC}[3,24,25]$. Most of these patients are referred in tertiary referral centers, either immediately or after having been unsuccessfully reoperated. Analyzing the long-term outcome of 38 patients referred for primary or secondary surgical repair of MBDI showed that reconstruction using RY with or without associated liver resection provided good long-term results in $79 \%$ of cases regardless of the number of previously performed surgeries. Surgical repair during a sepsis period or the presence of a biliary cirrhosis were independent risk factors of major postoperative complications or the recurrence of biliary stricture, respectively.

The current report highlights that the factor exerting the most important impact on long-term results was the presence of established liver cirrhosis due to chronic biliary obstruction at the time of surgical repair, a finding that to our knowledge has not been reported to date. These results confirm the work of Lokesh et al. in which the authors showed that the duration of biliary obstruction before repair was an independent factor of secondary stricture [26]. Parallel to this finding, and in line with numerous other reports, we showed that i) performing surgical repair during a sepsis period and the occurrence of major postoperative complications $(\mathrm{CDS}>3)$ were associated with an increased risk of biliary stricture recurrence $[12,19]$; ii) the level of the HJ was not a risk factor of anastomotic stricture [17,21], whereas others have shown that HJ performed high up to the right-left hepatic duct confluence is associated with an increased rate of failure [15]; iii) right hepatic artery obstruction at the time of LC was frequent but had no impact on long-term results after surgical repair, as it has previously been suggested [27,28]. This observation is, however, in opposition with the results of Sarno and colleagues [29], suggesting that patients with concomitant vascular and biliary injuries had worse outcomes.

To date, it is accepted that the safest way to repair MBDIs is Roux-en-Y HJ [14,15]. However, Moraca et al. reported similar long-term results after hepaticoduodenostomy (HD) or HJ [17] and recommended performing HD rather than HJ because the surgery can be completed more quickly, it is easier to perform and secondary endoscopic procedures are still possible when necessary. We believe that $\mathrm{HJ}$ remains the only way to divert the biliary tree at the level of confluence or above. In the present study, 9 patients had concomitant liver resection, and in these cases, an HD would not have been possible. 
Flum et al. [1] demonstrated increased mortality when the repairing surgeon was the same as the injuring surgeon, and several studies have confirmed this observation $[14,16,21,30]$. The results of the current work reveal no impact of pre-referral repair on outcome. Similarly, the timing of repair remains controversial. Although some studies have suggested a significant correlation between early repair and worse prognosis [12,14,28], others have found no impact of the time elapsed between injury and repair [16,18]. Recently, Pekolj et al, showed in a large single-center study, that the intraoperative repair of BDI performed during LC by experienced hepatobiliary surgeons either by open or laparoscopic approach appears of paramount importance to assure optimal results [31]. In fact, these contradictory results suggest that more than the timing of repair, it is the expertise of the surgeon who performs the surgery that may be the key to success $[16,19]$. The results obtained in the current study emphasize the need to minimize postoperative complications, which may be facilitated by referring patients to tertiary hepato-biliary $(\mathrm{HB})$ centers.

A major focus of interest of the present study lies in the long-term follow-up period. Indeed, failure of HJ may be symptomatic only several years after the initial repair. With a median follow-up period of 93 months, we found that $13 \%$ of our patients showed a post-repair stricture These results are in line with those of previous studies that have reported rates of post-repair strictures between $10 \%$ to $19 \%[12,19]$. In these patients, we prioritized surgical repair over endoscopic or radiological approaches with dilatation or stenting of the anastomosis [18,32]. Despite this aggressive approach, 2 of the 5 patients who underwent anastomotic repair developed secondary biliary cirrhosis and eventually underwent orthotopic liver transplantation (5.3\% of the 38 referred cases). The same results were previously reported by Schmidt et al., with a special focus on the delay of occurrence justifying prolonged oversight [19].

In conclusion, the treatment of MBDI remains a challenge requiring support at expert $\mathrm{HB}$ centers. Achieving repair by HJ provides good long-term results but should not be performed during a sepsis period in order to reduce major postoperative complications and an increased risk of anastomotic stricture. The presence of biliary cirrhosis was determined to be the only independent risk factor for anastomotic stricture in the current study. In these cases, liver transplantation should be discussed at an early stage. 


\section{REFERENCES}

[1] Flum DR, Cheadle A, Prela C, Dellinger EP, Chan L. Bile duct injury during cholecystectomy and survival in medicare beneficiaries. JAMA 2003 Oct 22;290(16):216873.

[2] Strasberg SM, Hertl M, Soper NJ. An analysis of the problem of biliary injury during laparoscopic cholecystectomy. J Am Coll Surg 1995 Jan;180(1):101-25.

[3] Tantia O, Jain M, Khanna S, Sen B. Iatrogenic biliary injury: 13,305 cholecystectomies experienced by a single surgical team over more than 13 years. Surg Endosc 2008 Apr;22(4):1077-86.

[4] Savassi-Rocha PR, Almeida SR, Sanches MD, Andrade MA, Frerreira JT, Diniz MT et Al. Iatrogenic bile duct injuries. Surg Endosc 2003 Sep;17(9):1356-61.

[5] Avgerinos C, Kelgiorgi D, Touloumis Z, Baltatzi L, Dervenis C. One Thousand Laparoscopic Cholecystectomies in a Single Surgical Unit Using the "Critical View of Safety" Technique. J Gastrointest Surg 2009 Mar;13(3):498-503.

[6] Strasberg SM. Avoidance of biliary injury during laparoscopic cholecystectomy. J Hepatobiliary Pancreat Surg 2002;9(5):543-7.

[7] Callery MP. Avoiding biliary injury during laparoscopic cholecystectomy: technical considerations. Surg Endosc 2006 Nov;20(11):1654-8.

[8] Fullum TM, Downing SR, Ortega G, Chang DC, Oyetunji TA, Van Kirk K et al. Is laparoscopy a risk factor for bile duct injury during cholecystectomy? JSLS 2013 ;17(3):36570)

[9] Andrew S. Does concentration of surgical expertise improve outcomes for laparoscopic cholecystectomy? 9 year audit cycle. Surgeon 2013 ;11(6): 309-12

[10] Sinha S, Hofman D, Stoker DL, Friend PJ, Poloniecki JD, Thompson MM et al.Epidemiological study of provision of cholecystectomy in England from 2000 to 2009: retrospective analysis of Hospital Episode Statistics Surg Endosc 2013 ;27(1):162-75 
[11] Stewart L, Robinson TN, Lee CM, Liu K, Whang K, Way LW. Right hepatic artery injury associated with laparoscopic bile duct injury: incidence, mechanism, and consequences. J Gastrointest Surg. 2004 Jul-Aug;8(5):523-30.

[12] Walsh RM, Henderson JM, Vogt DP, Brown N. Long-term outcome of biliary reconstruction for bile duct injuries from laparoscopic cholecystectomies. Surgery 2007 Oct;142(4):450-6.

[13] Bismuth H. Postoperative strictures of the bile duct. In The Biliary Tract, Blumgart LH (ed.). Clinical Surgery International. Churchill Livingstone: Edinburgh, 1982 ;5:209-218.

[14] De Reuver PR, Grossmann I, Busch OR, Obertop H, van Gulik TM, Gouma DJ. Referral pattern and timing of repair are risk factors for complications after reconstructive surgery for bile duct injury. Ann Surg 2007 May;245(5):763-70.

[15] Mercado MA, Chan C, Orozco H, Tielve M, Hinojosa CA. Acute bile duct injury. Surg Endosc 2003 Sep;17(9):1351-5.

[16] Perera T, Silva MA, Hegab B, Muralidharan V, Bramhall SR, Mayer AD et Al. Specialist early and immediate repair of post-laparoscopic cholecystectomy bile duct injuries is associated with an improved long-term outcome. Ann Surg 2011 Mar;253(3):553-60.

[17] Moraca RJ, Lee FT, Ryan JA Jr, Traverso LW. Long-term biliary function after reconstruction of major bile duct injuries with Hepaticoduodenostomy or Hepaticojejunostomy. Arch Surg 2002; 137:889-894

[18] Sicklick JK, Camp MS, Lillemoe KD, Melton GB, Yeo CJ, Campbell KA et Al. Surgical management of bile duct injuries sustained during laparoscopic cholecystectomy: perioperative results in 200 patients. Ann Surg 2005 May;241(5):786-92.

[19] Schmidt SC, Langrehr JM, Hintze RE, Neuhaus P. Long-term results and risk factors influencing outcome of major bile duct injuries following cholecystectomy. Br J Surg 2005 Jan;92(1):76-82.

[20] Pottakkat B, Sikora SS, Kumar A, Saxena R, Kapoor VK. Recurrent bile duct stricture: causes and long-term results of surgical management. J Hepatobiliary Pancreat Surg. 2007;14(2):171-6. 
[21] Huang CS, Lein HH, Tai FC, Wu CH. Long-term results of major bile duct injury associated with laparoscopic cholecystectomy. Surg Endosc 2003 Sep;17(9):1362-7.

[22] Sahajpal AK, Chow SC, Dixon E, Greig PD, Gallinger S, Wei AC. Bile duct injuries associated with laparoscopic cholecystectomy: timing of repair and long-term outcomes. Arch Surg 2010 Aug;145(8):757-63.

[23] Dindo D, Demartines N and Clavien PA. Classification of Surgical Complications. Ann Surg 2004 Aug;240(2):205-13.

[24]The Southern Surgeons Club. A prospective analysis of 1518 laparoscopic cholecystectomies. N Engl J Med 1991 ;324: 1075-1078.

[25] Roslyn JJ, Binns GS, Hughes EF, Saunders-Kirkwood K, Zinner MJ, Cates JA. Open cholecystectomy. A contemporary analysis of 42,474 patients. Ann Surg 1993 Aug;218(2):129-37.

[26] Lokesh HM, Pottakkat B, Prakash A, Singh RK, Behari A, Kumar A et al. Gut Liver $2103 ; 7(3): 352-6$

[27] Keleman AM, Imagawa DK, Findeiss L, Hanna MH, Tan VH, Katz MH et Al. Associated vascular injury in patients with bile duct injury during cholecystectomy. Am Surg 2011 Oct;77(10):1330-3.

[28] Pulitano C, Parks RW, Ireland H, Wigmore SJ, Garden OJ. Impact of concomitant arterial injury on the outcome of laparoscopic bile duct injury. Am J Surg 2011 Feb;201(2):238-44.

[29] Sarno G, Al-Sarira AA, Ghaneh P, Fenwick SW, Malik HZ, Poston GJ. Cholecystectomyrelated bile duct and vasculobiliary injuries. Br J Surg 2012 Aug;99(8):1129-36.

[30] Fischer CP, Fahy BN, Aloia TA, Bass BL, Gaber AO, Ghobrial RM. Timing of referral impacts surgical outcomes in patients undergoing repair of bile duct injuries". HPB 2009 Feb;11(1):32-7.

[31] Pekolj J, Alvarez FA, Palavecino M, Sanchez Claria R, Mazza O, de Santibanes E. Intraoperative management and repair of bile duct injuries sustained during 10,123 laparoscopic cholecystectomies in a high-volume referral center. J Am Coll Surg 2013; 216(5):894-901) 
[32] De Reuver PR, Rauws EA, Bruno MJ, Lameris JS, Busch OR, van Gulik TM et Al. Survival in bile duct injury patients after laparoscopic cholecystectomy: a multidisciplinary approach of gastroenterologists, radiologists, and surgeons. Surgery 2007 Jul;142(1):1-9. 
LEGENDS to Tables and Figures.

Table 1. Patients' characteristics

Table 2. Risk factors of major complications after repair

Table 3. Long-term results after hepaticojejunostomy to repair major bile duct injury after laparoscopic cholecystectomy

Figure 1. Flow chart of the study 
Table 1. Patients' characteristics

\begin{tabular}{|c|c|}
\hline Parameters & $\mathrm{n}=38(\%)$ \\
\hline Age (years) & $61 \pm 16$ \\
\hline Sex (male/female) & $15 / 23$ \\
\hline \multicolumn{2}{|l|}{ ASA Score } \\
\hline 1 & $12(32 \%)$ \\
\hline 2 & $16(42 \%)$ \\
\hline 3 & $10(26 \%)$ \\
\hline 4 & 0 \\
\hline Sepsis & $15(39 \%)$ \\
\hline Bilirubin over $2 \mathrm{~N}$ & $16(42 \%)$ \\
\hline Cholestasis over $2 \mathrm{~N}$ & $35(92 \%)$ \\
\hline Cirrhosis & $7(18 \%)$ \\
\hline \multicolumn{2}{|c|}{ Strasberg's Classification of BDI } \\
\hline E1 & $6(16 \%)$ \\
\hline $\mathrm{E} 2$ & $14(37 \%)$ \\
\hline E3 & $6(16 \%)$ \\
\hline E4 & $9(24 \%)$ \\
\hline E5 & $3(8 \%)$ \\
\hline Associated Vascular Injury & $10(26 \%)$ \\
\hline
\end{tabular}

E1: Common hepatic duct division, $>2 \mathrm{~cm}$ from bifurcation

E2: Common hepatic duct division, $<2 \mathrm{~cm}$ from bifurcation

E3: Common bile duct division at bifurcation

E4: Hilar stricture, involvement of confluence and loss of communication between right and left hepatic duct

E5: Involvement of aberrant right hepatic duct alone or with concomitant stricture of the common hepatic duct 
Table 2. Risk factors of major complications after repair

\begin{tabular}{|c|c|c|c|c|c|}
\hline \multirow[b]{2}{*}{ Parameters } & \multicolumn{2}{|c|}{ Major Morbidity } & \multirow[b]{2}{*}{$\begin{array}{c}\text { Univariate } \\
\mathrm{p}\end{array}$} & \multirow[b]{2}{*}{$\begin{array}{c}\text { Multivariable } \\
\text { OR - IC95\% }\end{array}$} & \multirow[b]{2}{*}{$\mathrm{p}$} \\
\hline & $\begin{array}{c}\text { Yes } \\
\mathrm{n}=10\end{array}$ & $\begin{array}{c}\text { No } \\
n=28\end{array}$ & & & \\
\hline Age (years) & $53.9 \pm 13$ & $63.7 \pm 16$ & 0.072 & $0.95[0.87 ; 1.01]$ & 0.123 \\
\hline Sex (male) & $4(40 \%)$ & $11(39 \%)$ & 1 & & \\
\hline Length of hospital stay (days) & $18 \pm 12$ & $10 \pm 9$ & 0.052 & - & - \\
\hline ASA Score & & & & & \\
\hline 1 & $3(30 \%)$ & $10(36 \%)$ & 0.806 & & \\
\hline 2 & $4(40 \%)$ & $12(43 \%)$ & & & \\
\hline 3 & $3(30 \%)$ & $6(21 \%)$ & & & \\
\hline Sepsis & $9(90 \%)$ & $6(21 \%)$ & $<0.001$ & $102.5[7.12 ; 11352]$ & 0.007 \\
\hline Cholestasis over $2 \mathrm{~N}$ & $9(90 \%)$ & $26(93 \%)$ & 1 & & \\
\hline Cirrhosis & $4(40 \%)$ & $3(11 \%)$ & 0.06 & - & - \\
\hline Bilirubin over $2 \mathrm{~N}$ & $6(60 \%)$ & $10(36 \%)$ & 0.267 & & \\
\hline Strasberg's Classification of BDI & & & 0.468 & & \\
\hline E1- E2 & $4(40 \%)$ & $16(57 \%)$ & & & \\
\hline E3 and more & $6(60 \%)$ & $12(43 \%)$ & & & \\
\hline Associated Vascular Injury & $2(20 \%)$ & $8(29 \%)$ & 0.699 & & \\
\hline Delay diagnosis & & & 0.35 & & \\
\hline immediate & $3(30 \%)$ & $15(54 \%)$ & & & \\
\hline intermediate & $5(50 \%)$ & $7(25 \%)$ & & & \\
\hline late & $2(20 \%)$ & $6(21 \%)$ & & & \\
\hline Delay to first repair before & & & & & \\
\hline Referral & & & 0.369 & & \\
\hline immediate & $3(30 \%)$ & $12(43 \%)$ & & & \\
\hline intermediate & $3(30 \%)$ & $4(14 \%)$ & & & \\
\hline late & $0(0 \%)$ & $4(14 \%)$ & & & \\
\hline First repair by referral & $6(60 \%)$ & $20(71 \%)$ & 0.694 & & \\
\hline Delay to referral & & & 1 & & \\
\hline immediate & $0(0 \%)$ & $0(0 \%)$ & & & \\
\hline intermediate & $1(10 \%)$ & $5(18 \%)$ & & & \\
\hline late & $9(90 \%)$ & $23(82 \%)$ & & & \\
\hline Number of anastomosis & & & 1 & & \\
\hline 1 & $3(30 \%)$ & $10(36 \%)$ & & & \\
\hline$>1$ & $7(70 \%)$ & $18(64 \%)$ & & & \\
\hline Level of anastomosis & & & 0.143 & $8.59[0.75 ; 252]$ & 0.121 \\
\hline CHD / confluence & $2(20 \%)$ & $14(50 \%)$ & & & \\
\hline IntraHepatic duct & $8(80 \%)$ & $14(50 \%)$ & & & \\
\hline Liver resection associated & & & 0.205 & & \\
\hline
\end{tabular}




\begin{tabular}{lr|ccccc} 
& No & $6(60 \%)$ & $23(82 \%)$ & & & \\
& Yes & $4(40 \%)$ & $5(18 \%)$ & & & \\
Roux en Y revision & & $2(20 \%)$ & $7(25 \%)$ & 1 & & \\
Anastomosis bile stenting & & $4(40 \%)$ & $19(68 \%)$ & 0.15 & $0.09[0.002 ; 1.18]$ & 0.116 \\
\hline
\end{tabular}


Table 3. Long-term results after hepaticojejunostomy to repair major bile duct injury after laparoscopic cholecystectomy

\begin{tabular}{|c|c|c|c|c|c|}
\hline Parameters & $\begin{array}{c}\text { Biliary } \\
\text { Stricture } \\
\text { Yes } \\
\mathrm{N}=5\end{array}$ & $\begin{array}{c}\text { No } \\
\mathrm{N}=33\end{array}$ & $\begin{array}{c}\text { Univariate } \\
\mathrm{p}\end{array}$ & $\begin{array}{c}\text { Multivariable } \\
\text { OR - IC95\% }\end{array}$ & $\mathrm{p}$ \\
\hline Age (years) & $61.2 \pm 13$ & $61.1 \pm 16$ & 0.991 & & \\
\hline Sex (male) & $3(60 \%)$ & $20(61 \%)$ & 1 & & \\
\hline ASA Score $(\mathrm{N}, \%)$ & & & 0.17 & & \\
\hline 1 & $1(20 \%)$ & $12(36 \%)$ & & & \\
\hline 2 & $1(20 \%)$ & $15(45 \%)$ & & & \\
\hline 3 & $3(60 \%)$ & $6(18 \%)$ & & & \\
\hline Sepsis & $5(100 \%)$ & $10(30 \%)$ & 0.006 & - & - \\
\hline Cholestasis over $2 \mathrm{~N}$ & $4(80 \%)$ & $31(94 \%)$ & 0.353 & & \\
\hline Cirrhosis & $4(80 \%)$ & $3(9 \%)$ & 0.002 & $26.4[2 ; 1018]$ & 0.026 \\
\hline Bilirubin over $2 \mathrm{~N}$ & $4(80 \%)$ & $12(36 \%)$ & 0.141 & $3.88[0.2 ; 166]$ & 0.387 \\
\hline Associated Vascular Injury & $1(20 \%)$ & $9(27 \%)$ & 1 & & \\
\hline Delay diagnosis & & & 0.839 & & \\
\hline immediate & $3(60 \%)$ & $15(45 \%)$ & & & \\
\hline intermediate & $1(20 \%)$ & $11(33 \%)$ & & & \\
\hline late & $1(20 \%)$ & $7(21 \%)$ & & & \\
\hline Delay to first repair before Referral & & & 1 & & \\
\hline immediate & $1(20 \%)$ & $12(36 \%)$ & & & \\
\hline intermediate & $3(60 \%)$ & $6(18 \%)$ & & & \\
\hline late & $1(20 \%)$ & $4(12 \%)$ & & & \\
\hline First repair by referral & $4(80 \%)$ & $22(67 \%)$ & 1 & & \\
\hline Delay to referral & & & 0.57 & & \\
\hline immediate & $0(0 \%)$ & $0(0 \%)$ & & & \\
\hline intermediate & $0(0 \%)$ & $3(9 \%)$ & & & \\
\hline late & $5(100 \%)$ & $27(82 \%)$ & & & \\
\hline Number of anastomoses & & & 0.64 & & \\
\hline 1 & $1(20 \%)$ & $12(36 \%)$ & & & \\
\hline$>1$ & $4(80 \%)$ & $21(64 \%)$ & & & \\
\hline Level of anastomosis & & & 0.374 & & \\
\hline CHD / confluence & $1(20 \%)$ & $15(45 \%)$ & & & \\
\hline IntraHepatic duct & $4(80 \%)$ & $18(55 \%)$ & & & \\
\hline Liver resection associated & & & 0.574 & & \\
\hline No & $3(60 \%)$ & $26(79 \%)$ & & & \\
\hline Yes & $2(40 \%)$ & $7(21 \%)$ & & & \\
\hline Roux en Y revision & $2(40 \%)$ & $7(21 \%)$ & 0.574 & & \\
\hline Anastomosis bile drain & $2(40 \%)$ & $21(64 \%)$ & 0.365 & & \\
\hline
\end{tabular}




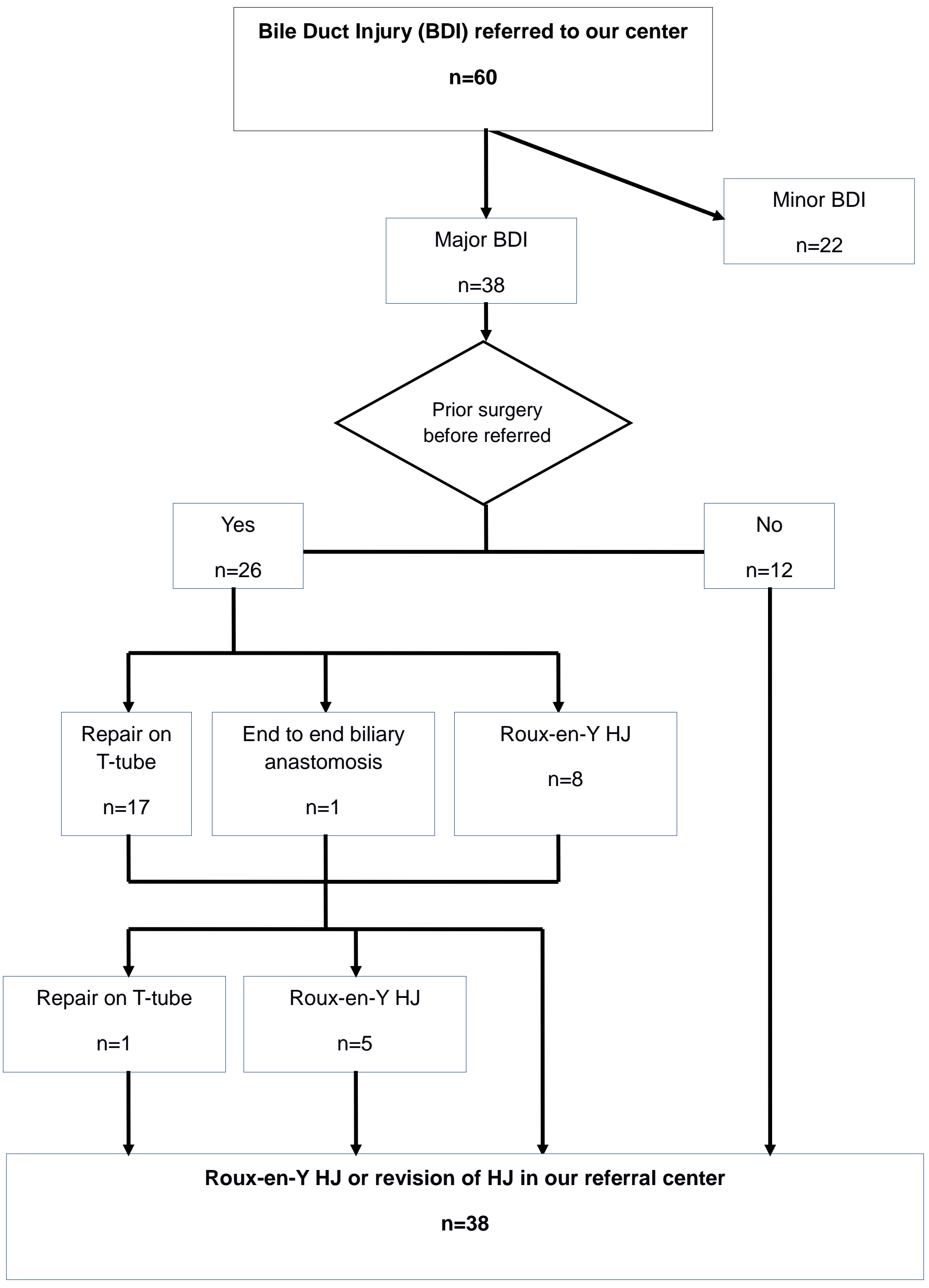


